\title{
Why Is Medical Care Expensive in the US?
}

\author{
Kaz Miyagiwa', Paul Rubin ${ }^{2}$ \\ ${ }^{1}$ Department of Economics, Florida International University, Miami, USA \\ ${ }^{2}$ Department of Economics, Emory University, Atlanta, USA \\ Email: paul.rubin@gmail.com
}

Received October 26, 2013; revised November 26, 2013; accepted December 3, 2013

Copyright (C) 2014 Kaz Miyagiwa, Paul Rubin. This is an open access article distributed under the Creative Commons Attribution License, which permits unrestricted use, distribution, and reproduction in any medium, provided the original work is properly cited. In accordance of the Creative Commons Attribution License all Copyrights (C) 2014 are reserved for SCIRP and the owner of the intellectual property Kaz Miyagiwa, Paul Rubin. All Copyright (C) 2014 are guarded by law and by SCIRP as a guardian.

\section{ABSTRACT}

America spends more on medical care than any other nation, with no noticeable difference in results. It is commonly thought that this is a result of a defect in the organization of medicine in the US, which can be repaired by "reform." However, medicine is a labor-intensive good and labor is more expensive in the US. We show that these conditions will invariably lead to a higher price and a higher percentage of GDP spent on medicine. Thus, while reforms may improve the functioning of the health care sector, they are unlikely to have a major effect on spending levels.

\section{KEYWORDS}

\section{Medical Care Expenditures; US Health Care Reform}

\section{Introduction}

One of the main factors underlying the desire to reform US medical care is the observation that the US spends much more on medical care than other wealthy countries. For example: "In Greece, the government and individuals combine to spend about $\$ 2300$ per capita on health care each year, and the average life expectancy is 79 years. Canada, where the hospitals are probably cleaner, spends about $\$ 3300$, and people live to about 80 . Here, in the United States, we spend more than $\$ 6000$, yet life expectancy is just below 78," [1]. The assumption is that the economic organization of medicine in the US is at fault and reorganization or reform will reduce the costs of medical care.

There are difficulties with the structure of the medical care market in the US. However, there may be other reasons why medical care costs more in the US. Medical care is a labor-intensive good (Baumol, 1993 [2]). Baumol [2] pointed out that costs of labor-intensive sectors such as health care would grow faster than costs of non-labor-intensive goods. Our argument here is related to but distinct from his work. We deal with the level of costs, not their growth, although our model is consistent with Baumol's [1] if we apply ours to the issue of growth. Our point is that the costs of labor-intensive goods will be higher in high wage economies. This higher level of costs is a result of the technology of production and the normal functioning of markets.

\section{Model}

We demonstrate the above result in a simple general equilibrium model. Suppose there are two countries, England and the US. Both countries produce two goods, medical care and a numeraire good, using two factors, capital and labor. Medicine is "labor-intensive" relative to the numeraire. Capital and labor are fixed in supply and freely mobile within each country. Perfect competition (or monopolistic competition) prevails everywhere. Technologies exhibit constant returns to scale and are identical across countries. Medicine is not traded internationally. The US is richer and so has more capital per capita. Under these assumptions we establish the following result.

Proposition: Suppose that medicine is price inelastic and income elastic. Then America pays a higher price for medicine and yet spends a greater fraction of its income on medicine compared with England.

To prove this result, we first present a general equilibrium model using dual functions (Dixit and Norman 1980 [3]). Let $p$ denotes the relative price of medicine 
(by Hicks' composite-commodity theorem we can lump all other goods together as a single composite good and use it as numeraire). Let $e(p, u)$ be the country's (minimum) expenditure function to attain the aggregate utility $u$, given $p$. Let $k$ denote the stock of capital, and let $r(p, k)$ be the country's (maximum) GDP function, given $p$ and $k$ (we suppress other factors of production to lighten notation). Both functions are assumed to be continuously differentiable in all their arguments.

The country's income-expenditure identity (budget constraint) is written

$$
e(p, u)=r(p, k) .
$$

The market-clearing condition for medicine is

$$
e_{p}(p, u)=r_{p}(p, k)
$$

where subscripts denote partial derivatives. Here, $e_{p}(p, u)$ is (Hicksian) demand for medicine and $r_{p}(p, k)$ is its supply function. By Walras' law the numeraire good market clears when conditions (1) and (2) hold. Thus, (1) and (2) completely specify the equilibrium. In particular, they determine the equilibrium $p$ and $u$ in terms of $k$ so we write $u=u(k)$ and $p=p(k)$.

To show the effect on the price of medicine from the difference in capital endowment between America and England, totally differentiate (1) and use (2) to obtain the welfare effect of a change in capital endowment

$$
\mathrm{d} u / \mathrm{d} k=r_{k} / e_{u} \text {. }
$$

A unit increase in capital raises GDP by $r_{k}$, which is the marginal value (price) of capital. Since $e_{u}=\partial e(p, u) / \partial u$ is the inverse of marginal utility of money, that increase in GDP raises national welfare by $r_{k} / e_{u}$. Next, differentiate (2) to obtain

$$
e_{p u} \mathrm{~d} u / \mathrm{d} k+S \mathrm{~d} p / \mathrm{d} k=r_{p k}
$$

where

$$
S \equiv e_{p p}-r_{p p}<0 .
$$

Here, $e_{p p}<0$ is the slope of the Hicksian demand function whereas $r_{p p}>0$ is the slope of the supply curve of medicine. Thus, $\mathrm{S}$ denotes the slope of the net (Hicksian) demand for medicine. Substituting from (3) into (4) yields the effect on the price of medicine

$$
\mathrm{d} p / \mathrm{d} k=\left(r_{p k}-r_{k} e_{p u} / e_{u}\right) / S .
$$

To sign the right-hand side expression, note that $r_{p k}<0$ since medicine is labor-intensive; this is the Rybczynski effect. Next, if we let $m(p, y)$ denote the ordinary (Marshallian) demand function for medicine at income $y$, we have $e_{p u} / e_{u}=\partial m / \partial y=m_{y}$, the marginal propensity to consume medicine. Since medicine is not an inferior good, this term is positive. This makes the numerator on the right-hand side of (6) negative and hence $\mathrm{dp} / \mathrm{d} k>0$, meaning that the price of medicine is higher in the US than in Britain. Note that, this result does not depend on the income or price elasticity of demand for medicine.

To prove that the Americans spend a larger fraction of their incomes on medicine than the British, let $q$ denote the expenditure share of medicine, that is,

$$
q \equiv p m / r=p r_{p}(p, k) / r(p, k),
$$

where $r_{p}=e_{p}=m$ by (2). Differentiating (7) yields

$$
\mathrm{d} q / \mathrm{d} k=N / r^{2}
$$

with

$$
N \equiv\left(r r_{p}+p r r_{p p}-p r_{p}^{2}\right) \mathrm{d} p / \mathrm{d} k+p\left(r r_{p k}-r_{p} r_{k}\right) .
$$

Thus, $\mathrm{d} q / \mathrm{d} k$ is positive if and only if $N$ is positive. After long manipulation (see the appendix), we have

$$
N=(1-\varepsilon) A+(\eta-1) B \text {. }
$$

Here, $\varepsilon \equiv-p m_{p} / m$ is the price elasticity of medicine, $\eta \equiv-y m_{y} / m$ is the income elasticity of medicine, and $A$ and $B$ are defined as follows:

$$
\begin{aligned}
& A=\left(r r_{p k}-r_{p} r_{k}\right)\left(r_{p} / S\right)>0 \\
& B=\left[q r_{p k}-r_{p} r_{k}\left(1+r_{p} \phi\right)\right]\left(r_{p} / S\right)>0
\end{aligned}
$$

where $\phi \equiv p r_{p p} / r_{p}$ is the supply elasticity of medicine. Since medicine is price inelastic $(\varepsilon<1)$, if $\eta \geq 1$, i.e., medicine has income elasticity equal to or greater than one, $N>0$ and hence $\mathrm{d} q / \mathrm{d} k>0$, meaning that America spends a greater fraction of its income on medicine.

The above proof assumes perfect competition. However, due to the isomorphism between perfect competition and monopolistic competition (Dixit and Norman, 1980 [2]), the proposition holds even if there is monopolistic competition in medical care industry.

Demand for medicine is clearly price inelastic, generally estimated at between 0 and 0.5 (Getzen, 2010, [4]). In contrast, estimates of income elasticity vary significantly, depending on the methodology used and the variables included in the equation. Recent studies estimate income elasticity to be less than one for individuals but greater than one for countries, the latter generally estimated at about 1.3 (Getzen 2000 [5]; 2010, [4]). Gerdtham and Jönsson (2000 [6]) put the income elasticity at about one but at a higher range if unadjusted for an impact of technology and insurance. Others dissent; e.g., Baltagi and Moscone (2010 [7]) find lower elasticity estimates for OECD countries. The controversy over whether medicine is a necessity or a luxury remains unsettled.

Note however that medicine being a luxury $(\eta \geq 1)$ is only sufficient but not necessary for the conclusion of our result. Even if income elasticity is less than one, America can still spend a significantly larger share of income on medicine than England because of low price elasticity of medicine. Since the income share on medi- 
cine is still small ( $q=0.17$ for the US in 2011), the term $A$ can dominate the term $B$ in (8) if medicine is sufficiently supply inelastic such that $\mathrm{d} q / \mathrm{d} k>0$ even if $\eta<$ 1.

\section{Conclusion}

To conclude, the fact that Americans are paying disproportionately more for medicine may be a simple reflection of the nature of the economy, not of flaws in the market system. If this analysis is correct, we cannot expect major changes in expenditure patterns as a result of reforms, whether they are the sort of reforms associated with "Obamacare" or the more pro-market reforms favored by the Republicans. In either case, delivery of medical care may become more or less efficient, and there may be other costs and benefits, but a major shift in spending patterns is not likely to occur. Differences in spending patterns across countries noted by critics are due to inherent structural differences in the economies, not to any particular flaw in the American organization of medical care.

\section{REFERENCES}

[1] D. Leonhardt, “A Lesson from Europe on Health Care,” New York Times, 2006.

[2] W. J. Baumol, "Health Care, Education and the Cost Disease: A Looming Crisis for Public Choice,” In: C.
Rowley, F. Schneider and R. D. Tollison, Eds., The Next Twenty-Five Years of Public Choice, Springer, Netherlands, 1993, pp. 17-28. http://dx.doi.org/10.1007/978-94-017-3402-8_3

[3] A. K. Dixit and V. Norman, "Theory of International Trade," Oxford University Press, Oxford, 1980. http://dx.doi.org/10.1017/CBO9780511628627

[4] E. T. Getzen, "Health Economics and Financing," 4th Edition, John Wiley \&Sons, Hoboken, 2010.

[5] T. E. Getzen, "Health Care Is an Individual Necessity and a National Luxury: Applying Multilevel Decision Models to the Analysis of Health Care Expenditures," Journal of Health Economics, Vol. 19, No. 2, 2000, pp. 259-270. http://dx.doi.org/10.1016/S0167-6296(99)00032-6

[6] U. Gerdtham and B. Jönsson. "International Comparison of Health Expenditure,” In: A. J. Culyer and J. P. Newhouse, Eds., Handbook of Health Economics, North-Holland, 2000, pp. 11-53.

[7] B. H. Baltagi and F. Moscone, "Health Care Expenditure and Income in the OECD Reconsidered: Evidence from Panel Data,” Economic Modelling, Vol. 27, No. 4, 2010, pp. 804-811. http://dx.doi.org/10.1016/j.econmod.2009.12.001 


\section{Appendix: Derivation of Equation (8)}

Substituting for $\mathrm{d} q / \mathrm{d} k$ from (5) and collecting terms, we can express $N$ as

$$
\begin{aligned}
N & =\left(r r_{p}+p r r_{p p}-p r_{p}^{2}\right)\left(r_{p k}-r_{k} m_{y}\right) / S+p\left(r r_{p k}-r_{p} r_{k}\right) \\
& =\left(r_{p k} / S\right)\left[r r_{p}+p r r_{p p}-p r_{p}^{2}+p r S\right]-\left(r_{k} / S\right)\left[m_{y}\left(r r_{p}+p r r_{p p}-p r_{p}^{2}\right)+p r_{p} S\right]^{.}
\end{aligned}
$$

Substituting for $S$ from (6), we can rewrite the first bracketed term of (9) as

$$
r r_{p}+p r r_{p p}-p r_{p}^{2}+p r S=r_{p}\left(r-p r_{p}\right)+p r e_{p p} .
$$

Substituting for $S$ and $m_{y}=\eta m / y=\eta r_{p} / r$ from the definition of the income elasticity $\eta$, we can rewrite the second bracketed term as

$$
\begin{aligned}
& m_{y}\left(r r_{p}+p r r_{p p}-p r_{p}^{2}\right)+p r_{p} S \\
& =\left(\eta r_{p} / r\right)\left(r r_{p}+p r r_{p p}-p r_{p}^{2}\right)+p r_{p} e_{p p}-p r_{p} r_{p p} \\
& =\left(\eta r_{p} / r\right)\left[r_{p}\left(r-p r_{p}\right)\right]+p r_{p} e_{p p}+(\eta-1) p r_{p} r_{p p} \\
& =\left(r_{p} / r\right)\left[r_{p}\left(r-p r_{p}\right)+p r e_{p p}\right]+(\eta-1)\left(r_{p} / r\right)\left[r_{p}\left(r-p r_{p}\right)\right]+(\eta-1) p r_{p} r_{p p} \\
& =\left(r_{p} / r\right)\left[r_{p}\left(r-p r_{p}\right)+p r e_{p p}\right]+(\eta-1)\left[r_{p}^{2}\left(r-p r_{p}\right) / r+p r_{p} r_{p p}\right]
\end{aligned}
$$

Substitute these expressions into the expression for $N$ to obtain

$$
N=\left(r_{p k}-r_{k} r_{p} / r\right)\left[r_{p}\left(r-p r_{p}\right)+p r e_{p p}\right] / S-(\eta-1)\left[\left(r_{p}^{2} / r\right)\left(r-p r_{p}\right)+p r_{p} r_{p p}\right] r_{k} / S
$$

Since $r$ is homogeneous of degree one in prices, we have that $r-p r_{p}>0$. Thus, the second term is non-negative if $\eta$ $\geq 1$. The first term is positive if the slope of the Hicksian demand $e_{p p}$ is not too small. To make "too small" more precise, define the price elasticity of the Hicksian demand for medicine by $\theta \equiv-p e_{p p} / e_{p}$ and rewrite the first bracketed term as:

$$
r_{p}\left(r-p r_{p}\right)+p r e_{p p}=r_{p}\left\{\left(r-p r_{p}\right)-r \theta\right\}=r r_{p}\{(1-q)-\theta\}
$$

By the standard operations, the Slutsky equation

$$
e_{p p}=m_{p}+m_{y}(p, y) m
$$

can be expressed as

$$
-\theta=-\varepsilon+q \eta
$$

using $\varepsilon \equiv-p m_{p} / m$, the price elasticity of Marshallian demand for medicine. Then,

$$
1-q-\theta=1-\varepsilon+q(\eta-1)
$$

Thus, the first bracketed term is rewritten

$$
r r_{p}[1-\varepsilon-q(\eta-1)]
$$

Substituting the above expression into $N$ and rearranging the result, we have

$$
\begin{aligned}
N & =\left(r r_{p k}-r_{k} r_{p}\right)[(1-\varepsilon)+q(\eta-1)] r_{p} / S-(\eta-1)\left[\left(r_{p}^{2} / r\right)\left(r-p r_{p}\right)+p r_{p} r_{p p}\right] r_{k} / S \\
& =\left(r r_{p k}-r_{k} r_{p}\right)[(1-\varepsilon)+q(\eta-1)] r_{p} / S-(\eta-1)\left[(1-q) r_{p}+p r_{p p}\right] r_{k}\left(r_{p} / S\right) \\
& =(1-\varepsilon)\left(r r_{p k}-r_{k} r_{p}\right)\left(r_{p} / S\right)+(\eta-1)\left[q r r_{p k}-r_{k} r_{p}\left(1+p r_{p p}\right)\right]\left(r_{p} / S\right)
\end{aligned}
$$

Denote the supply elasticity of medicine by $\phi=p r_{p p} / r_{p}$. Then $N$ is written

$$
N=(1-\varepsilon) A+(\eta-1) B \text {, }
$$

where $A$ and $B$ are as defined in the text. 